\title{
Is Thermal Power Plant Regulation in China Constructive?
}

\author{
Hongbing $\mathrm{Li}^{1}$, Ronghua $\mathrm{Ju}^{2 *}$ \\ ${ }^{1}$ School of Geosciences and Resources, China University of Geosciences, Beijing, China \\ ${ }^{2}$ College of Economics and Management, China Agricultural University, Beijing, China

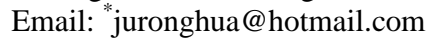

Received May 8, 2012; revised June 7, 2012; accepted June 16, 2012

\begin{abstract}
This paper analyzes main legal requirements for thermal power plants in China, which is intended to save energy and reduce discharge by restricting coal consumption for power generation. However, based on our four cases of the selection of thermal power plant construction proposals, which provide the ideal contrast of two different regulation circumstances, we find that state-owned firms, which strictly follow the regulations, cannot realize the efficient use of energy and capital. In contrast, private firms, which are more able to follow the principle of profit maximization and dare to breach the regulation policy, can realize the efficient use of energy and capital. Then using the fixed-ratio production function, this paper suggests regulation not only results in energy and capital waste, but also employment opportunity loss. Expanding this conclusion, this paper proposes that the more regulation, the more employment opportunity loss. Therefore, if the government can deregulate the regulated sectors, more labor can be combined with the capital of new entrants, and the income distribution will be more equitable.
\end{abstract}

Keywords: Thermal Power Plant; Regulation; Employment Opportunity Loss

\section{Introduction}

The power sector is regulated heavily in China. There are regulations on entry, technique, or price for power generation, transmission and sales. Thermal power plants (TPPs) are just a part of the power sector, about which this paper will consider the effect of regulation.

There are two contrasting opinions about government regulation on economic activities, which are based on different assumptions. One is the public interest theory of regulation [1], which suggests that a free market has some failures such as monopoly power, moral hazard, adverse selection and externalities. Therefore, the government, which is assumed to behave for social welfare maximization, should provide regulations to solve these market failures. Another opinion is the public choice theory, which assumes government regulators are rational and not altruistic. This opinion has two strands. One is the theory of interest group, which considers that regulation is acquired by the industry and is designed and operated primarily for its benefit [2]. The other is the theory of rentseeking, suggests that regulation is pursued for the benefit of politicians and bureaucrats [3-5]. Politicians use regulation both to create rents and to extract them through campaign contributions, votes, and bribes.

Some empirical research has tested these theories. The empirical results of Djankov et al., based on data from 85

\footnotetext{
"Corresponding author.
}

countries, demonstrate that countries with heavier regulation of entry have higher corruption and larger unofficial economies, but not better quality of public or private goods [6]. Bertrand and Kramarz [7] studied the effects of entry regulation on employment in the retail sector in France, and find that entry regulation decreases retail employment, partly due to the increase in concentration and the ensuing price upturns.

In this paper, we summarize the main legal requirements for TPPs in China, then analyze four firms' scheme selection of thermal power plant construction to contrast regulation and deregulation circumstances, and find that regulation results in the firm's energy waste. Based on this finding, utilizing a Leontief function, we conclude that the regulation results in employment opportunity loss.

\section{Several Concepts Related to Thermal Power Plants}

In order to better understand the context of TPP regulation in China, we will explain some basic concepts about TPPs.

A TPP may be either an independent firm, which supplies products in the market, or a firm's division, which supplies products to other divisions of this firm. In this paper, we mainly deal with the TPP affiliated to a firm. There are two kinds of products in a TPP, power and heat (steam or hot water, in most cases, steam). Steam is the main product of a TPP, and power is the byproduct. Firms may demand power or steam, but often both. They 
can get power and steam from the market, or produce it themselves. In most cases, firms build their own boilers to produce steam, but whether they produce power themselves depends on the economic and technical evaluation.

Steam can be categorized as high-pressure, mediumpressure or low-pressure. When a firm needs steam of different pressure levels, the boiler can only supply the highest-pressure level, and the lower-pressure level steam can be obtained by means of a Desuperheater and Decompressor, a Back pressure Steam Turbine, or a Condense Turbine with Extraction Steam. The latter two methods are usually called cogeneration of heat and power. The firm will lose usable power if it transforms the higherpressure steam to the lower-pressure one by means of a Desuperheater and Decompressor, instead of the cogeneration of heat and power. Cogeneration can produce more power than a Desuperheater and Decompressor. However, the method of cogeneration requires more investment. For the specific project, the firm should comprehensively consider such factors as incremental investment, saved out-purchasing power, power price, coat price, operating hours, industry policy, etc. to decide which method should be taken. According to most of engineering practices, it is favorable to select the method of cogeneration of heat and power for the vast majority of firms and the whole society. However, firms that would benefit from the method of cogeneration do not necessarily select this method. We will disclose the reason for a firm's selection in the following parts.

\section{Thermal Power Plant Regulation in China}

TPP regulation in China is contained in some governmenttal regulations, see Table 1.
The above regulations are followed by TPPs. Regulation 2 is the extension of regulation 1 . Regulation 3, 4 and 5 contain the technical requirements, which provide for the cases that: the power ratio of the TPP is $100 \%$, and genenral annual average thermal efficiency is more than $45 \%$. For industrial users, if they meet one of above two requirements, they should meet both. According to engineering experience in China, if the general power ratio of the TPP is more than $45 \%$, the power ratio of power generation is about $40 \%$, and the standard coal consumption for power generation is about $307 \mathrm{~g} / \mathrm{kwh}$. Providing the power ratio for its own use is $13 \%$, the reflected standard coal consumption for power supply is $353 \mathrm{~g} / \mathrm{kwh}$. Table 2 sets out the average standard coal consumption for power generation of China and the United States.

The core contents of China's TPP regulations stress the index of thermal efficiency, which is an advanced objective for the medium and small TPPs. The rush construction of TPPs caused the local governments not to encourage the construction of medium and small TPPs since 2004, and some provinces even prohibited the construction. Therefore, the ratification of medium and small TPPs becomes difficult. Some provinces only ratify Back Pressure Steam Turbine just because it is easier to check for the Government; other provinces don't ratify any TPPs.

Regulation 6, promulgated by State Development and Reform Committee and Ministry of Construction in 2007, made the above trend of cautious ratification into law. Compared with the former regulations, it kept the requirement of thermal efficiency and the ratio of power unchanged, and added three points, including:

- Encouraging the combination of cogeneration of heat and power with comprehensive utilization;

Table 1. Regulations about thermal power plants.

\begin{tabular}{|c|c|c|c|}
\hline No. & Title of regulation & Publishing government department & Publishing date \\
\hline 1 & $\begin{array}{l}\text { An announcement approved and transmitted the State Economic and } \\
\text { Trade Commission’s interim provision on several questions of } \\
\text { developing holistic utilization of resources by the State Council. }\end{array}$ & The State Council. & 1985 \\
\hline 2 & $\begin{array}{l}\text { An announcement approved and transmitted the State Economic and } \\
\text { Trade Commission's interim provision on several questions of further } \\
\text { developing holistic utilization of resources by the State Council. }\end{array}$ & The State Council. & 1996 \\
\hline 3 & Several provisions on developing co-generation of heat and power. & $\begin{array}{l}\text { State Planning Commission, State Economic and Trade } \\
\text { Commission, Ministry of Electric Power, Ministry of } \\
\text { Construction. }\end{array}$ & 1998 \\
\hline 4 & Provisions on developing co-generation of heat and power. & $\begin{array}{l}\text { The State Planning Commission, State Economic and } \\
\text { Trade Commission, Ministry of Construction. }\end{array}$ & 2000 \\
\hline 6 & $\begin{array}{l}\text { Provisional regulation of management of projects of co-generation } \\
\text { and generation by holistic utilization of coal gangue. }\end{array}$ & $\begin{array}{l}\text { National Development and Reform Commission, } \\
\text { Ministry of Construction. }\end{array}$ & 2007 \\
\hline
\end{tabular}


Table 2. Average standard coal consumption for power generation of China and the United States (g/kwh).

\begin{tabular}{ccccc}
\hline Year & 1998 & 1999 & 2000 & 2001 \\
China & 373 & 369 & 363 & 360 \\
United States & 346 & 342 & 340 & 357 \\
\hline
\end{tabular}

- Encouraging Back Pressure Steam Turbines, and Condense Turbine with Extraction Steams not less than $200 \mathrm{MW}$;

- Encouraging combining cogeneration of heat and power with local heating supply.

However, so many encouragements result in prohibition.

The causes are as follows:

- The firm that requires cogeneration of heat and power may not have resources such as coal gangue, coal slurry, coal gas, etc. to use comprehensively.

- The thermal efficiency of the Back Pressure Steam Turbines is higher, but the power generation load floats with the heat load variation, which makes the power generation unstable. Therefore, firms would choose the Back Pressure Steam Turbines accompanied by Condense Turbine with Extraction Steams to keep the heat and electricity stable. If the Back Pressure Steam Turbine is only ratified, how can the Condense Turbine with Extraction Steam be obtained? It is worthy to encourage Condense Turbine with Extraction Steams not less than $200 \mathrm{MW}$, but where are the huge heat load and the enormous amount of fund going to come from?

- Regional heating is mostly supplied by the government, but cogeneration of heat and power is mostly done by enterprise. It is difficult to combine them, although the government encouraged their combination. In fact, these combinations mostly use the falsely documented regional heating supply to approve genuine cogeneration of heat and power project.

The core of cogeneration policy is to restrict standard coal consumption. According to engineering experience, energy consumption accounts for about $75 \%$ of the cost of power generation, therefore, reducing the standard coal consumption could decrease the cost of power generation. The intention of the government regulation is to decrease the cost of power generation by setting the ceiling for standard coal consumption, which would be a good thing. However, can this objective be realized by the requirement of governmental regulations? We should continue to analyze the measurement of coal consumption.

Both coal consumption of power generation and the average annual thermal efficiency can't be found by simple product check and calculation. The power ratio is calculated by accumulating heat and power (sometimes influenced by subjective factors). Due to these limitations, it is impossible to judge whether the Condense Turbine with Extraction Steam reaches the requirements for the regulation of cogeneration in 1998. Therefore, the medium-small Condense Turbine with Extraction Steams is basically prohibited under the regulation 6 of 2007, effectively the central government has converted index control to an equipment control. Some local governments also administer TPPs like this way in the practice. However, the equipment control is also invalid because supervision bodies can't supervise all of the processes of project construction. Even if they can supervise all of the processes, they definitely need some specialists, who have to be prevented from buying off, to carry it out.

\section{State-Owned Firms Strictly Following Regulations Are Wasting Energy}

In this section, we will discuss how a firm selects the TPP construction proposal under the above regulations, based on data from four sample firms. ${ }^{1}$

In order to observe the influence of regulation on firm behavior, we classify our sample firms into two groups. One group is state-owned firms whose mechanism is more rigid, including Firm A and Firm B, which follow the regulations strictly; and the other is private firms whose mechanism is more flexible, including Firm $\mathrm{C}$ and Firm D, which might contravene the regulations for profit maximization.

Firm A is a large state-owned firm whose main products are Synthetic ammonia, urea, chlorine-alkali, and methanol. Firm A's power is supplied by the local power supply bureau: the subsidy power price for chemical fertilizer use is RMB ¥0.26 per kilowatt-hour (kwh), and the price for other uses is RMB ¥0.46 per kwh. Chemical production needs some medium-pressure steam to drive the turbine, therefore Firm A built a medium-pressure boiler. However it also needs microtherm and low pressure steam, and hopes to build a Back Pressure Steam Turbine to more efficiently use energy to produce power, but this project is required to be ratified by the government. Considering the difficulty of ratification, Firm A had to construct a Desuperheater and Decompressor for ensuring smooth operation. However, this process results in energy waste of about 32,400,000 kwh electric power annually (if 7200 hours yearly), which amounts to 11,700 tons standard coal. (See Table 3) If there was no government regulation, Firm A would choose the method of cogeneration of heat and power to build a Back Pressure Steam Turbine to produce electricity and save money.

Firm B is a large state-owned heat supplier, and supplies low-pressure steam to the market. Because Firm B

\footnotetext{
${ }^{1}$ To protect these firms' business secrets, we name these four firms A, $\mathrm{B}, \mathrm{C}$, and D respectively. Without particular statement, the technical and economic data are all from feasibility study reports or practical design materials of X Engineering Design Co., Ltd. The data's utilization has been granted by this company. Special declaration: the data is only for academic discussion and without any business purpose.
} 
is a large steam supplier, its best operation mode is to build a TPP of cogeneration. In 2007, Firm B had planned to build a TPP, but the project still hasn't been ratified by the government, and it has to continue to supply steam by means of Desuperheater and Decompressor and waste a large quantity of energy. Table 4 shows the steam cost and standard coal consumption of the current production mode, and those of cogeneration calculated in a feasibility study report. Compared with the indices of feasibility study report, the current mode of Desuperheater and Decompressor consumes an additional 52,600 tons standard coal per year, provided the price of per ton standard coal is RMB ¥ 450 , Firm B loses RMB $¥ 23,657,000$ profit annually. $^{2}$

Firm $\mathrm{C}$ is a large private coal firm. In the process of coal production, it produces a large quantity of byproducts such as coal gangue, coal slurry, coal gas, and so on, which can't be sold and pollute the environment. Therefore, in 2003 Firm C decided to build a TPP to burn out these wastes and increase power supply at the same time. Obviously, it is impossible for Firm $C$ to meet the requirement. However, it is necessary and favorable to implement this project for Firm C, although the government requirements are breached. As a result, it invested RMB ¥96,000,000 to build 3 boilers of $75 \mathrm{t} / \mathrm{h}$ and 2 generators of $12 \mathrm{MW}$ without governmental approval. Because the byproducts, as wastes, were provided to the TPP free, the cost of electric power is less than RMB $¥ 0.13$ per kwh although the thermal efficiency of small plant is very low. Given 7200 hours per year, compared with the normal price of RMB $¥ 0.46$ in the market, Firm C could save RMB $¥ 42,800,000$ power expenses. ${ }^{3}$ The huge economic benefit drove Firm $C$ to set up another $2 \times 25 \mathrm{MW}$ generator in 2006 and put it into production, still without governmental approval.

Table 3. Firm A's energy waste comparing to cogeneration of heat and electricity.

\begin{tabular}{cc}
\hline Electricity loss (kwh) & Equals to standard coal waste (ton) \\
\hline $32,400,000$ & 11,700 \\
\hline
\end{tabular}

Data source: the feasibility study report of X Engineering Design Co., Ltd.

Table 4. Firm B's current index and those in feasibility study report.

\begin{tabular}{ccc}
\hline Index & $\begin{array}{c}\text { Cost of steam } \\
(\mathrm{RMB} / \mathrm{ton})\end{array}$ & $\begin{array}{c}\text { Standard coal } \\
\text { consumption of steam } \\
\text { (ton/ton) }\end{array}$ \\
\hline $\begin{array}{c}\text { Desuperheater and } \\
\text { Decompressor } \\
\text { Cogeneration of heat } \\
\text { and electricity }\end{array}$ & 81.74 & 0.17 \\
\hline
\end{tabular}

Data source: the feasibility study report of X Engineering Design Co., Ltd.

${ }^{2}$ Yearly Steam Supply Quantity is taken as 1,315,000 Tons.

${ }^{3} \mathrm{RMB} \quad ¥ 42,800,000=24,000 \times 0.75 \times 7200 \times(0.46-0.13) / 10,000$.
Firm D is a large private firm, constructed on the Gobi in 2003, and put into production in 2005, whose main products are Coke and methanol. After two years of operation, the owner found that there is huge energy waste as the medium-pressure steam transformed into low-pressure steam by means of Desuperheater and Decompressor. If a Condense Turbine with Extraction Steam was added, the waste steam would generate power $12,000 \mathrm{kw}$ in winter and $9000 \mathrm{kw}$ in summer, and increase power production by $84,000,000$ kw per year. Firm D finally built Condense Turbine with Extraction Steam, which is written as Back Pressure Steam Turbine in the application materials for the ratification convenience. According to the local coal price, the cost of power production is only RMB $¥ 0.2$ per kwh, much less than the price of power grid, RMB Y0.49.

The above cases provide the ideal contrast of two different regulation circumstances. Firm A and Firm B, who are state-owned, strictly follow the regulations. In this regulation circumstance, Firms can't realize the efficient use of energy and capital. However the private firms, such as Firm C and Firm D, are more able to follow the principle of profit maximization and dare to breach the regulation policy. In this deregulation circumstance, Firms can realize the efficient use of energy and capital.

\section{Regulation and Employment Opportunity Loss}

Other than wasting energy, the TPP regulation also results in employment opportunity loss.

To be useful, labor should be combined with material resources (collectively referred to as capital) to get payment. Regulation prevents labor, which should happen without regulation, from happening. We make the following proposition:

TPP regulation results in employment opportunity loss.

In order to prove this proposition, we make the following assumptions:

1) There are only two factors of production: capital and labor;

2) Firm's production function is fixed-ratio: $\mathrm{f}(l, k)=$ $\min \{l, k\}$, where $l$ is the labor that the firm employs, and $k$ is the capital that the firm invests.

Figure 1 represents the fixed-ratio production function. For state-owned Firm A or Firm B in the above cases, the combination of capital $K_{1}$ and labor $L_{1}$ will produce production $Q_{1}$, the combination of capital $K_{2}$ and labor $L_{2}$ will produce production $Q_{2}$. Now the firm such as A or B possesses capital $K_{3}$, and their production quantity only reaches $Q_{1}$. However if there is no regulation, these firms can add capital $K_{3} K_{2}$, and they will employ additional labor $L_{1} L_{2}$ to produce production $Q_{2}$. Due to regulation, new TPP can't be ratified, and capital $K_{3} K_{2}$ can't be invested. This results in a part of capital, which equals to 


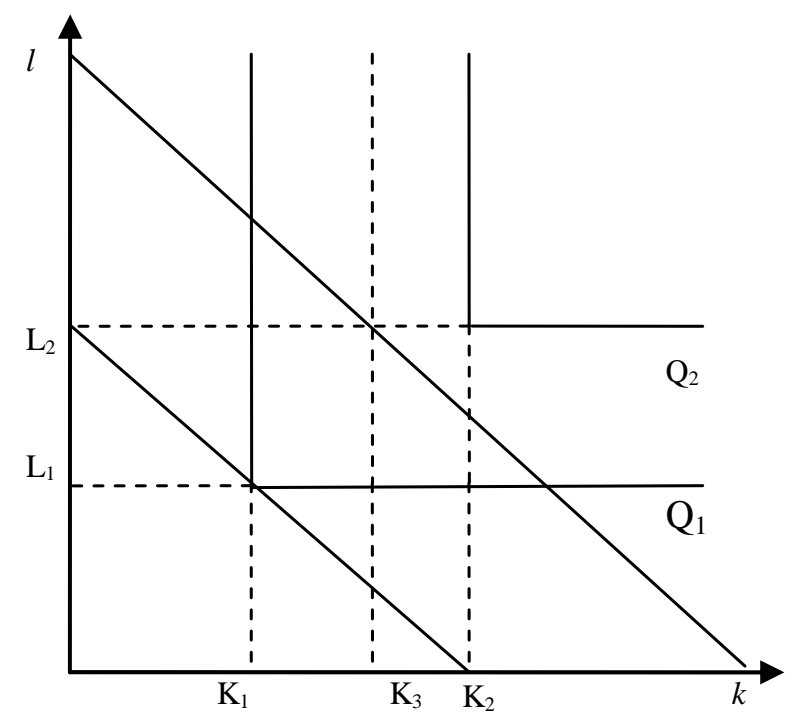

Figure 1. Employment opportunity loss resulting from TPP regulation.

$K_{1} K_{3}$, left unused, which can't combine with additional labor $L_{1} L_{2}$. Therefore, its production quantity can't reach $Q_{2}$, but only $Q_{1}$, and the employment opportunity loss resulting from regulation is $L_{1} L_{2}$. For private Firm C or D in above cases, nevertheless, they have enough incentive to breach the regulation to pursue profit maximization and invest additional capital to build new TPP to employ more labor and get more production quantity $Q_{2}$.

State-owned firms obey governmental regulation policy strictly. However, tight regulation prevents labor, which should happen without regulation, from happening, resulting in employment opportunity loss. For the group of non-state firms, they have enough incentive to violate regulations to maximize their profit, and their less marginal capital combines with more labor.

In the same way, we can expand our conclusion. If there is regulation in one industry, employment opportunity loss will occur. Because new capital can't enter this industry, the labor, which should be combined with the new capital, can't happen. Peoples and Talley [8] tests the hypothesis that ocean transportation deregulation presents owner-operators with greater job opportunities and the opportunity to increase earnings at port cities and find that, compared to the pre-deregulation period, a greater share of owner-operator drivers are employed at port cities in the shipping post-deregulation period. Anticompetitive business regulations, like price controls and administrative obstacles to start a new business also appear to lower labor force participation and employment rates [9]. Ebell and Haefke [10] find that a decrease of less than two-tenths of a percentage point of unemployment rates can be attributed to product market deregulation.

We can express the relationship between regulation and employment opportunity as Figure 2. For example, if there is a low level of regulation, $R_{1}$, in one economic entity $C_{1}$, then there would be more employment opportunities, $E_{1}$, in $\mathrm{C}_{1}$; on the contrary, if there is a high level of regulation, $R_{2}$, in another economic entity $\mathrm{C}_{2}$, then there would be less employment opportunities, $E_{2}$ in $C_{2}$. Consequently, $E_{1} E_{2}$ is the employment opportunity loss of economic entity $C_{1}$ resulting from regulation, compared with economic entity $\mathrm{C}_{2}$. Cardullo [11] studied the effects of product and labor market deregulation on wage inequality and welfare, and showed that deregulation of goods market has mixed effects on inequality: the wage variance and the Gini index are lower, but the ratio of the highest over the lowest wage paid in the economy increases.

\section{Conclusions and Discussion}

Is the TPP regulation helpful for the development of this industry? It's not. Regulation results in energy waste and employment opportunity loss.

On one hand, in China, regulation is almost everywhere in the economy. It spreads in many industries, such as the power, petroleum, telecom, railway, finance, healthcare, designing, installation, civil engineering, trade and security sectors, etc, too numerous to mention. On the other hand, the contrast of payments between ordinary sectors and regulated sectors is distinct. The income of the majority of the population is very low, but the income of employees in regulated industries is high.

Therefore, the conclusion of this paper has distinct policy implications. If the government can deregulate the regulated sectors, more labor can be combined by the new capital of entrants, the income distribution will be more equitable, and the welfare of consumers will be improved.

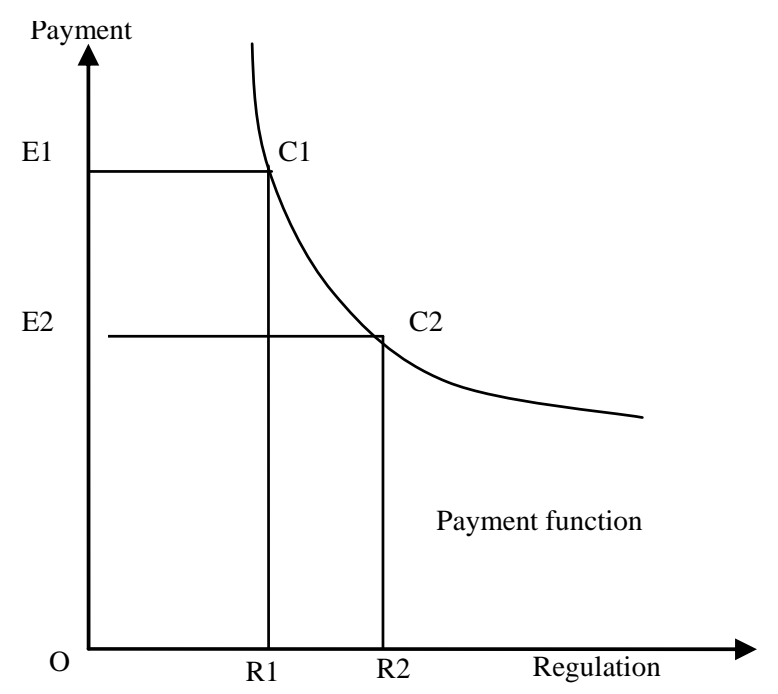

Figure 2. Relationship between the employment and regulation. 


\section{Acknowledgements}

The authors would like to thank Dr. Lingyun He from College of Economics and Management of China Agricultural University, and Dr. Sarah Boswell, an alumnus of University of Wisconsin-Madison for their insightful comments and constructive suggestions. All errors are the authors' sole responsibility. We also thank the Fundamental Research Funds for the Central Universities for the financial support.

\section{REFERENCES}

[1] A. C. Pigou, "The Economics of Welfare," 4th Edition, Macmillan and Co., London, 1938.

[2] G. J. Stigler, “The Theory of Economic Regulation,” Bell Journal of Economics and Management Science, Vol. 2, No. 1, 1971, pp. 3-21. doi:10.2307/3003160

[3] G. Tullock, "The Welfare Cost of Tariffs, Monopoly, and Theft,” Western Economic Journal, Vol. 5, No. 3, 1967, pp. 224-232.

[4] A. O. Krueger, "The Political Economy of Rent-Seeking Society,” The American Economic Review, Vol. 64, No. 3, 1974, pp. 291-310.

[5] R. D. Tollison, "Rent Seeking: A Survey,” Kyklos, Vol. 35, No. 4, 1982, pp. 575-602. doi:10.1111/j.1467-6435.1982.tb00174.x
[6] S. Djankov, R. L. Porta, F. Lopez-de-Silanes and A. Shleifer, “The Regulation of Entry,” Quarterly Journal of Economics, Vol. 117, No. 1, 2002, pp. 1-37. doi:10.1162/003355302753399436

[7] M. Bertrand and F. Kramarz, "Does Entry Regulation Hinder Job Creation? Evidence from the French Retail Industry,” Quarterly Journal of Economics, Vol. 107, No. 4, 2002, pp. 1369-1413. doi:10.1162/003355302320935052

[8] J. Peoples and W. K. Talley, “Owner-Operator Truck Driver Earnings and Employment: Port Cities and Deregulation,” Transportation Labor Issues and Regulatory Reform Research, Vol. 10, 2004, pp. 191-213.

[9] H. Feldmann, "Business Regulation, Labor Force Participation and Employment in Industrial Countries,” Journal of Economics and Business, Vol. 61, No. 3, 2009, pp. 238-260. doi:10.1016/j.jeconbus.2008.06.002

[10] M. Ebell and C. Haefke, "Product Market Deregulation and the US Employment Miracle," Review of Economic Dynamics, Vol. 12, No. 3, 2009, pp. 479-504. doi:10.1016/j.red.2008.11.002

[11] G. Cardullo, “The Distributive and Welfare Effects of Product and Labour Market Deregulation,” Labour Economics, Vol. 18, No. 2, 2011, pp. 205-217. doi:10.1016/j.labeco.2010.10.003 